\title{
Heat stress impacts on wheat growth and yield were reduced in the Huang-Huai-Hai Plain of China in the past three decades
}

\author{
Fulu Tao ${ }^{\mathrm{a}, \mathrm{c}, *}$, Zhao Zhang $^{\mathrm{b}}$, Shuai Zhang ${ }^{\mathrm{a}}$, Reimund P. Rötter ${ }^{\mathrm{c}}$ \\ a Institute of Geographical Sciences and Natural Resources Research, Chinese Academy of Sciences, Beijing 100101, China \\ b State Key Laboratory of Earth Surface Processes and Resource Ecology, Beijing Normal University, Beijing 100875, China \\ c Natural Resources Institute Finland (Luke), FI-01301 Vantaa, Finland
}

\section{A R T I C L E I N F O}

\section{Article history:}

Received 12 March 2015

Received in revised form 26 July 2015

Accepted 6 August 2015

Available online 27 August 2015

\section{Keywords:}

Adaptation

Crop production

Cultivars

Extreme climate

Impacts

Phenology

\begin{abstract}
A B S T R A C T
Heat stress impacts on crop growth and yield have been investigated by controlled-environment experiments, however little is known about the impacts under field conditions at large spatial and temporal scales, particularly in a setting with farmers' autonomous adaptations. Here, using detailed experiment observations at 34 national agricultural meteorological stations spanning from 1981 to 2009 in the HuangHuai-Hai Plain (HHHP) of China, we investigated the changes in climate and heat stress during wheat reproductive growing period (from heading to maturity) and the impacts of climate change and heat stress on reproductive growing duration (RGD) and yield in a setting with farmers' autonomous adaptations. We found that RGD and growing degree days above $0{ }^{\circ} \mathrm{C}$ (GDD) from heading to maturity increased, which increased yield by $\sim 14.85 \%$, although heat stress had negative impacts on RGD and yield. During 1981-2009, high temperature $\left(>34^{\circ} \mathrm{C}\right.$ ) degree days (HDD) increased in the northern part, however decreased in the middle and southern parts of HHHP due to advances in heading and maturity dates. Change in HDD, together with increase in GDD and decrease in solar radiation (SRD), jointly increased wheat yield in the northern and middle parts but reduced it in the southern part of HHHP. During the study period, increase in GDD and decrease in SRD had larger impacts on yield than change in HDD. However, with climate warming of $2^{\circ} \mathrm{C}$, damage of heat stress on yield may offset a large portion of the benefits from increases in RGD and GDD, and eventually result in net negative impacts on yield in the northern part of HHHP. Our study showed that shifts in cultivars and wheat production system dynamics in the past three decades reduced heat stress impacts in the HHHP. The insights into crop response and adaptation to climate change and climate extremes provide excellent evidences and basis for improving climate change impact study and designing adaptation measures for the future.
\end{abstract}

(c) 2015 Elsevier B.V. All rights reserved.

\section{Introduction}

Wheat (Triticum aestivum) is the most widely grown crop in the world. About $21 \%$ of the world's food depends on the wheat Crop, which grows on 220 million hectares of farmland worldwide (http://www.fao.org). As a crop that prefers relatively cool temperatures, climate change can strongly affect wheat growth and yields in many regions of the world (Tao et al., 2006, 2012a; Ortiz et al., 2008; Lobell et al., 2011, 2012; Olesen et al., 2011; Trnka et al., 2014; Asseng et al., 2015). Since critical temperature thresholds and sensitivities vary between cultivars and phenological development stages (Porter and Gawith, 1999), impacts of temperature change on wheat growth and yields are complex and diverse. The

\footnotetext{
* Corresponding author.

E-mail address: taofl@igsnrr.ac.cn (F. Tao).
}

impacts of heat stress on crop yield have been investigated by controlled-environment experiments (Wall et al., 2011), however little is known about the effects under field conditions at large spatial and temporal scales (Siebert and Ewert, 2014). Recently, impacts of heat stress on crop growth and yields have also been estimated by crop simulation models (Challinor et al., 2005; Asseng et al., 2011, 2015; Tao and Zhang, 2013) and statistical approaches (Lobell et al., 2012; Gourdji et al., 2013; Liu et al., 2014). However, modeling crop response to extreme events like heat waves is still in its infancy so far, although it is receiving increasing levels of attention and is now a particular research focus for crop modeling (Challinor et al., 2005; Tao et al., 2009; Rötter et al., 2011; Lobell et al., 2012). The statistical modeling approaches are often limited by the lack of detailed crop growth and yield data. For example, in order to quantify the impacts of heat stress on crop yield, detailed data on major phenological events such as flowering are essential to match weather variables with farm-specific 
crop growth phases; however the data are not available in most previous studies. Moreover, the cultivar diversity and heterogeneity in sowing and flowering dates observed in field (Siebert and Ewert, 2012; Tao et al., 2012b) are still not reflected in large scale heat stress assessments (Siebert and Ewert, 2014). Due to these important shortcomings, the impacts assessments of heat stress on crop production at large spatial and temporal scales remain quite uncertain and imperfectly understood (Rötter et al., 2011; Asseng et al., 2011; 2015; Lobell et al., 2012; Tao and Zhang, 2013 Lobell et al., 2012; Tao and Zhang, 2013), particularly in the field, a setting with farmers' autonomous adaptations such as shifts of sowing dates and crop cultivars (Reidsma et al., 2010). There is currently a clear need to investigate the sensitivity of crop growth and yields to heat stress under field conditions, as well as the roles of agronomic management and cultivars changes in improvement of heat tolerance, in contrasting environments, to support the development and adaptation of crops to a warmer climate (Siebert and Ewert, 2014).

China is the world's largest wheat producer, and accounts for about a fifth of global wheat production and consumption. Previous studies based on census yield data and mean crop growth duration, taking the country as a whole, showed that wheat yields were negatively affected by climate change in the past three decades, although there were quite large spatial differences (Lobell et al., 2011; Tao et al., 2012a). Recently more detailed experiment observations at national agricultural meteorological stations across the primary wheat production regions in China became available, which allows us to obtain insights into the impacts of climate change and heat stress on wheat growth and yields in a setting with farmers' autonomous adaptations.

In the present study, using the detailed experiment observations at 34 national agricultural meteorological stations spanning from 1981 to 2009 in the Huang-Huai-Hai Plain (HHHP) of China (Fig. 1), we aim to (1) investigate the changes in climate and extreme high temperature during the wheat growing period in the past three decades; (2) investigate the sensitivity of wheat growing duration and yields to climate change and extreme high temperature; (3) quantify the impacts of changing climate and extreme high temperature on wheat growing duration and yields in the past three decades in a setting with farmers' autonomous adaptations. Finally, we discuss the variations in the sensitivity of different wheat cultivars, shifts of major phenological dates and their implications on adaptation measures.

\section{Materials and methods}

\subsection{Stations and data}

The HHHP is the primary winter wheat producing area in China, where wheat cultivation area takes up more than $60 \%$ of the total in China. In this study, detailed experimental observations at 34 national agricultural meteorological stations spanning from 1981 to 2009 in the HHHP are used, which are maintained by the China Meteorological Administration (CMA). The experimental records include major wheat phenological dates, yields, and major management practices such as irrigation and fertilization. In addition, CMA also compiled the observed records of major agricultural meteorological disasters such as heat and drought stress based on the monthly reports from each agricultural meteorological station since 1991 (http://cdc.nmic.cn/). These agricultural meteorological disasters were observed and recorded by the well-trained agricultural technicians at each station following a standardized observation method (China Meteorological Administration, 1993) across the stations. As an example, heat stress on wheat was recorded when extreme high temperature occurred and wheat leaves and spike color changing from yellowish green to yellow- ish white or yellowish brown, leaves withering and rolling, etc. The records included the station, name of agricultural meteorological disaster, crop species, occurrence date, degree of damage, intensity of disaster, area and percentage of damage, etc (Zhang et al., 2014).

According to wheat cultivation zones in China (Tong, 1992), the stations are grouped into three cultivation zones, i.e., Zone I, Zone II and Zone III (Fig. 1). These zones were created to reflect differences in biophysical conditions such as soil, climate and cropping system (Tong, 1992). The typical cropping system is rotation between winter wheat and summer maize in Zone I and Zone II; and is rotation between winter wheat and rice in Zone III. The mean climate from wheat heading to maturity and its trend during 1981-2009 in each zone are shown in Table 1.

Historical daily whether data, including minimum $\left(T_{\min }\right)$, maximum $\left(T_{\max }\right)$ and mean $\left(T_{\text {mean }}\right)$ temperature, solar radiation (SRD), sunshine duration and precipitation, for the agricultural meteorological stations from 1980 to 2009 were also obtained from CMA. Daily solar radiation at some stations where there was no solar radiation observation was estimated using sunshine duration observation and the Angstrom-Prescott equation (Prescott, 1940). Error analyses show that biases in the estimates are low, the root mean square error (RMSE) and the coefficient of determination $\left(R^{2}\right)$ between the observed and estimated SRD time series is $3.23 \mathrm{MJm}^{-2} \mathrm{day}^{-1}$ and 0.80 , respectively.

The detailed phenological records at the experiment stations provide a unique opportunity to matching of weather variables with farm-specific sowing, flowering and harvesting dates and wheat growth phases in each year. Crop management practices at the experiment stations were generally the same as the local management practices. Irrigation and fertilizer were used several times every year, and pesticides were used to control pests and diseases.

\subsection{Calculations of growing degree days (GDD) and high temperature degree days (HDD)}

Growing degree days (GDD) was calculated from hourly temperature values obtained by fitting a sine curve to daily $T_{\min }$ and $T_{\text {max }} . T_{t}$ is hourly temperature; $t$ is the hour of a day. $T_{t}$ in hour $t$ of a day is calculated from $T_{\min }$ and $T_{\max }$ as:

$$
\begin{aligned}
& T_{t}=\frac{T_{\min }+T_{\max }}{2}+\frac{T_{\max }-T_{\min }}{2} \times \sin \left(\frac{3.14}{12 \times t}\right) \\
& G D D=\sum_{t=1}^{N} D D_{t}
\end{aligned}
$$

$D D_{t}=\left\{\begin{array}{lll}0 & \text { if } & T_{t}<T_{\text {base }} \\ T_{t}-T_{\text {base }} & \text { if } & T_{\text {base }} \leq T_{t} \leq T_{o p t} \\ T_{\text {opt }}-T_{\text {base }} & \text { if } & T_{t}>T_{\text {opt }}\end{array}\right\}$

where $t$ is the hourly time step, $N$ is the total number of hours in the season and DD is growing degree days. A base temperature $\left(T_{\text {base }}\right)$ of $0^{\circ} \mathrm{C}$ and an optimum temperature $\left(T_{\text {opt }}\right)$ of $30^{\circ} \mathrm{C}$ were used in the study. In addition, the accumulation of degree days over $34^{\circ} \mathrm{C}$ from heading date to maturity date, termed high temperature degree days (HDD), was also computed as Lobell et al. (2012). Since the observed heading date and maturity date in each year at each station were used, GDD and HDD were jointly affected by changes in climate, cultivars and agronomic management. We further used the CMA independent observed records of heat stress occurrence to validate the performance of HDD in describing heat stress event.

\subsection{Regression models}

For Zone I, Zone II and Zone III, respectively, the effects of GDD and HDD on reproductive growing duration (RGD, from head- 


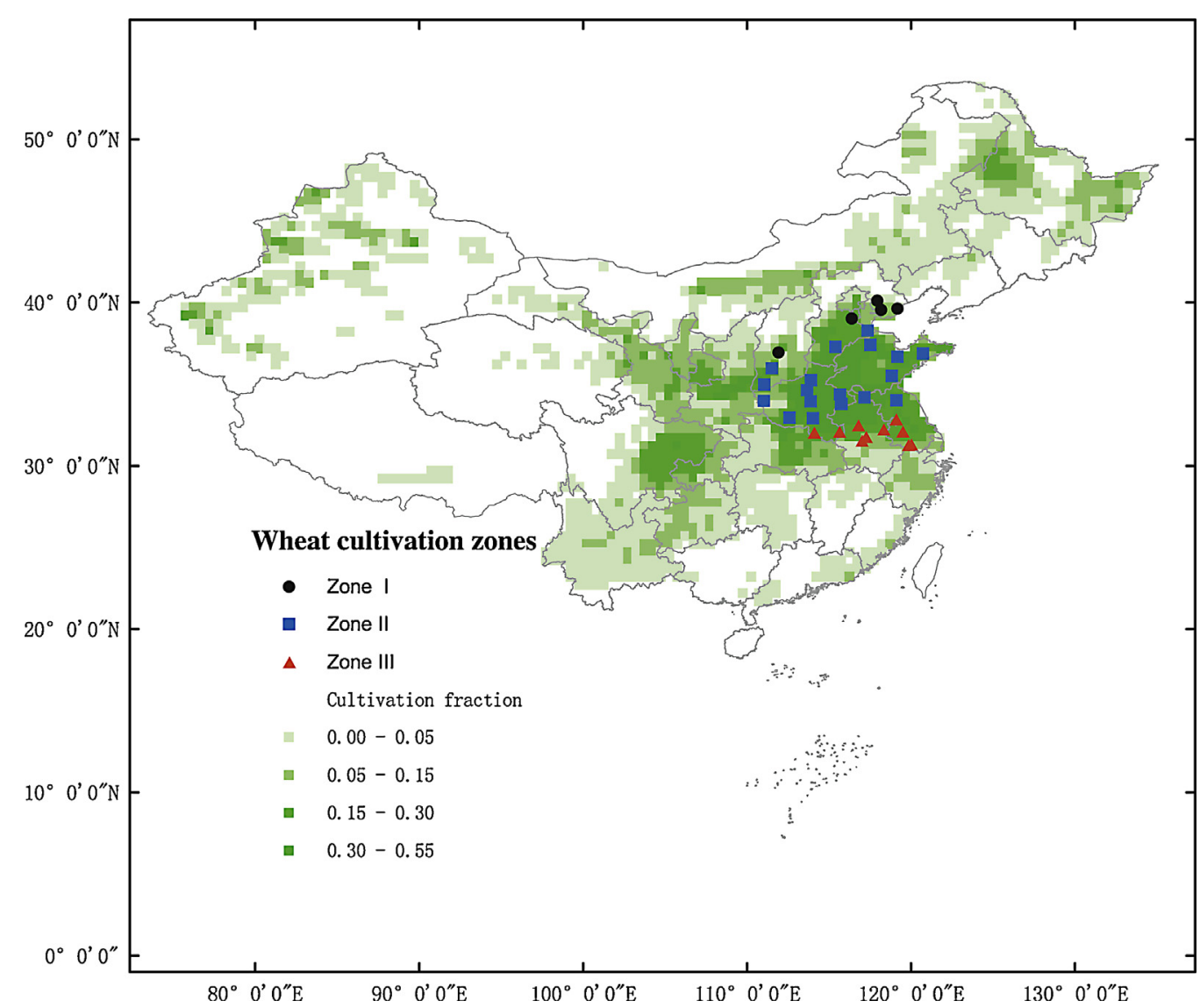

Fig. 1. Wheat cultivation fraction, the agricultural meteorological experiment stations and the zones in the Huang-Huai-Hai Plain of China used in the study.

\section{Table 1}

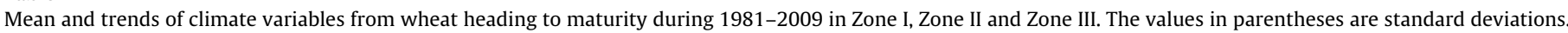
The trends with '*' are significantly at 0.05 level, and with '**' are significantly at 0.01 level.

\begin{tabular}{|c|c|c|c|}
\hline Climate variables & Zone I & Zone II & Zone III \\
\hline Tmean $\left({ }^{\circ} \mathrm{C}\right)$ & $21.55(1.143)$ & $20.31(1.21)$ & $19.97(1.18)$ \\
\hline Trend in Tmean $\left({ }^{\circ} \mathrm{C}_{\text {year }}{ }^{-1}\right)$ & $0.015^{* *}(0.015)$ & $-0.0046(0.0065)$ & $-0.0099(0.0092)$ \\
\hline $\operatorname{Tmax}\left({ }^{\circ} \mathrm{C}\right)$ & $28.09(1.26)$ & $26.45(1.66)$ & $25.08(1.49)$ \\
\hline Trend in $\operatorname{Tmax}\left({ }^{\circ} \mathrm{C} /\right.$ year $)$ & $0.026(0.02)$ & -0.0001736 & $-0.0077(0.012)$ \\
\hline Precipitation (mm) & $75.12(54.04)$ & $80.37(58.82)$ & $121.11(57.15)$ \\
\hline Trend in precipitation $\left(\mathrm{mm}\right.$ year $\left.^{-1}\right)$ & $-0.38(0.69)$ & $-0.016(0.32)$ & $-0.42(0.44)$ \\
\hline $\operatorname{SRD}\left(\mathrm{MJm}^{-2} \mathrm{day}^{-1}\right)$ & $19.81(1.34)$ & $18.17(1.88)$ & $15.83(1.98)$ \\
\hline Trend in SRD (MJm ${ }^{-2}$ day $^{-1}$ year $\left.^{-1}\right)$ & $-0.054^{* *}(0.02)$ & $-0.019(0.01)$ & -0.00048 \\
\hline GDD (degree-hour) & $20149.14(1741.34)$ & 20103.98(1991.12) & $20326.14(1758.71)$ \\
\hline Trend in GDD(degree-hour year ${ }^{-1}$ ) & $79.06^{* *}(21.06)$ & $75.38^{* *}(10.21)$ & $90.90^{* *}(12.45)$ \\
\hline HDD (degree-hour) & $12.61(21.24)$ & $9.81(18.02)$ & $2.41(5.88)$ \\
\hline Trend in HDD(degree-hour year ${ }^{-1}$ ) & $0.53^{* *}(0.27)$ & -0.02231 & -0.00405 \\
\hline
\end{tabular}

ing date to maturity date) and yield were investigated. For each zone, the time-series data from the respective weather stations were combined into a panel dataset and a panel analysis was subsequently carried out. To estimate the effects of GDD, HDD and precipitation on RGD, a linear regression applied to each of three zones was as follows:

$\mathrm{RGD}=\beta_{0 \mathrm{l}}+\beta_{\mathrm{sl}}+\beta_{\mathrm{Yl}}$ year $+\beta_{\mathrm{Gl}} \mathrm{GDD}+\beta_{\mathrm{Hl}} \mathrm{HDD}+\beta_{\mathrm{Pl}} \mathrm{PRE}+\epsilon_{\mathrm{l}}$

where $\beta_{01}$ is an intercept, $\beta_{\mathrm{sl}}$ refers to station fixed effects, $\beta_{\mathrm{Yl}}$ represents the long-term trend in RGD due to climatic and no-climatic factors, $\beta_{\mathrm{Gl}}, \beta_{\mathrm{Hl}}$ and $\beta_{\mathrm{Pl}}$ represent the sensitivity of RGD to GDD, HDD and precipitation (PRE), respectively, and $\epsilon_{1}$ is an error term.

To estimate the effects of GDD, HDD and SRD on wheat yield, a linear regression applied to each of the three zones was as follows:
Yield $=\beta_{\text {oy }}+\beta_{\text {sy }}+\beta_{\text {Yy year }}+\beta_{\mathrm{Gy}} \mathrm{GDD}+\beta_{\mathrm{Hy}} \mathrm{HDD}+\beta_{\mathrm{Py}} \mathrm{SRD}+\epsilon_{\mathrm{y}}$

where $\beta_{0 \mathrm{y}}$ is an intercept, $\beta_{\text {sy }}$ refers to station fixed effects, $\beta_{\mathrm{Yy}}$ represents the long-term trend in yield due to climatic and noclimatic factors, $\beta_{\mathrm{Gy}}, \beta_{\mathrm{Hy}}$ and $\beta_{\mathrm{Py}}$ represent the sensitivity of yield to GDD, HDD, and SRD, respectively, and $\epsilon_{\mathrm{y}}$ is an error term.

\subsection{Variations in sensitivity of different cultivars to GDD, $H D D$ and precipitation}

We selected ten popularly used cultivars during 1981-2009 across the HHHP, i.e., C1, C2, C3, C4, C5, C6, C7, C8, C9 and C10, to further investigate the differences in the sensitivities of the vari- 
Table 2

Correlations between RGD and GDD, HDD, precipitation, SRD, yield, as well as between yield and GDD, HDD, precipitation, SRD. Correlations with '*' are significant at 0.05 level, and with '**' are significant at 0.01 level.

\begin{tabular}{llll}
\hline Zones & & RGD & Yield \\
\hline Zone I & GDD & $0.83^{* *}$ & $0.20^{*}$ \\
& HDD & -0.05 & -0.10 \\
& Precipitation & $0.28^{* *}$ & -0.01 \\
& SRD & -0.03 & 0.06 \\
Zone II & Yield & $0.23^{*}$ & \\
& GDD & $0.87^{* *}$ & $0.26^{* *}$ \\
& HDD & -0.03 & -0.03 \\
& Precipitation & 0.01 & -0.02 \\
Zone III & SRD & $-0.44^{* *}$ & $0.13^{* *}$ \\
& Yield & $0.23^{* *}$ & \\
& GDD & $0.81^{* *}$ & 0.09 \\
& HDD & $-0.15^{*}$ & $0.14^{*}$ \\
& Precipitation & $0.37^{* *}$ & $-0.22^{* *}$ \\
& SRD & $-0.30^{* *}$ & $0.38^{* *}$ \\
\hline
\end{tabular}

ous cultivars to GDD, HDD, precipitation and SRD. The information on names of the cultivars, the stations where the cultivars were used, the time period when the cultivars were used, as well as the typical heading date and maturity date of the cultivars, was presented in Table S1. For each of the cultivars, the time-series data from the respective experimental stations where it was used were combined into a panel dataset. A panel analysis was subsequently carried out to investigate the cultivar sensitivities of RGD and yield to GDD and HDD using Eqs. (4) and (5), respectively.

\subsection{Estimating the effects of GDD and HDD on wheat RGD and yield during 1981-2009 and for local temperature increase of $1^{\circ} \mathrm{C}$ and $2{ }^{\circ} \mathrm{C}$}

We computed the changes in GDD, HDD, precipitation and SRD from wheat heading date to maturity date during 1981-2009 by a linear trend. Then the effects of changes in GDD and HDD on RGD and yield during 1981-2009 were estimated using Eqs. (4) and (5), respectively. To estimate the effects of GDD and HDD on RGD and yield for temperature increase of $1^{\circ} \mathrm{C}$ and $2{ }^{\circ} \mathrm{C}$, firstly assuming daily $T_{\min }$ and $T_{\max }$ from wheat heading date to maturity date increase by $1{ }^{\circ} \mathrm{C}$ and $2{ }^{\circ} \mathrm{C}$, respectively, we used (Eqs. (1)-(3) to compute the changes in GDD and HDD for temperature increase of $1{ }^{\circ} \mathrm{C}$ and $2{ }^{\circ} \mathrm{C}$. Then the effects of the changes in GDD and HDD on RGD and yield were estimated again using Eqs. (4) and (5), respectively. The trained Eqs. (4) and (5) included the information on cultivars change through the parameters of GDD and HDD because the GDD and HDD were associated with cultivars change.

\section{Results}

\subsection{Correlations between RGD, yield and GDD, $H D D$, precipitation, SRD}

RGD was significantly and positively correlated with GDD and precipitation, however negatively correlated with HDD (Table 2). Yield was significantly and positively correlated with GDD and SRD (Table 2). Yield and RGD were significantly and positively correlated, particularly in Zone I and Zone II.

In addition, the correlation between HDD and observed heat stress occurrence frequency was significant for Zone II and Zone III (Fig. 2), suggesting HDD represent heat stress occurrence fairly well.
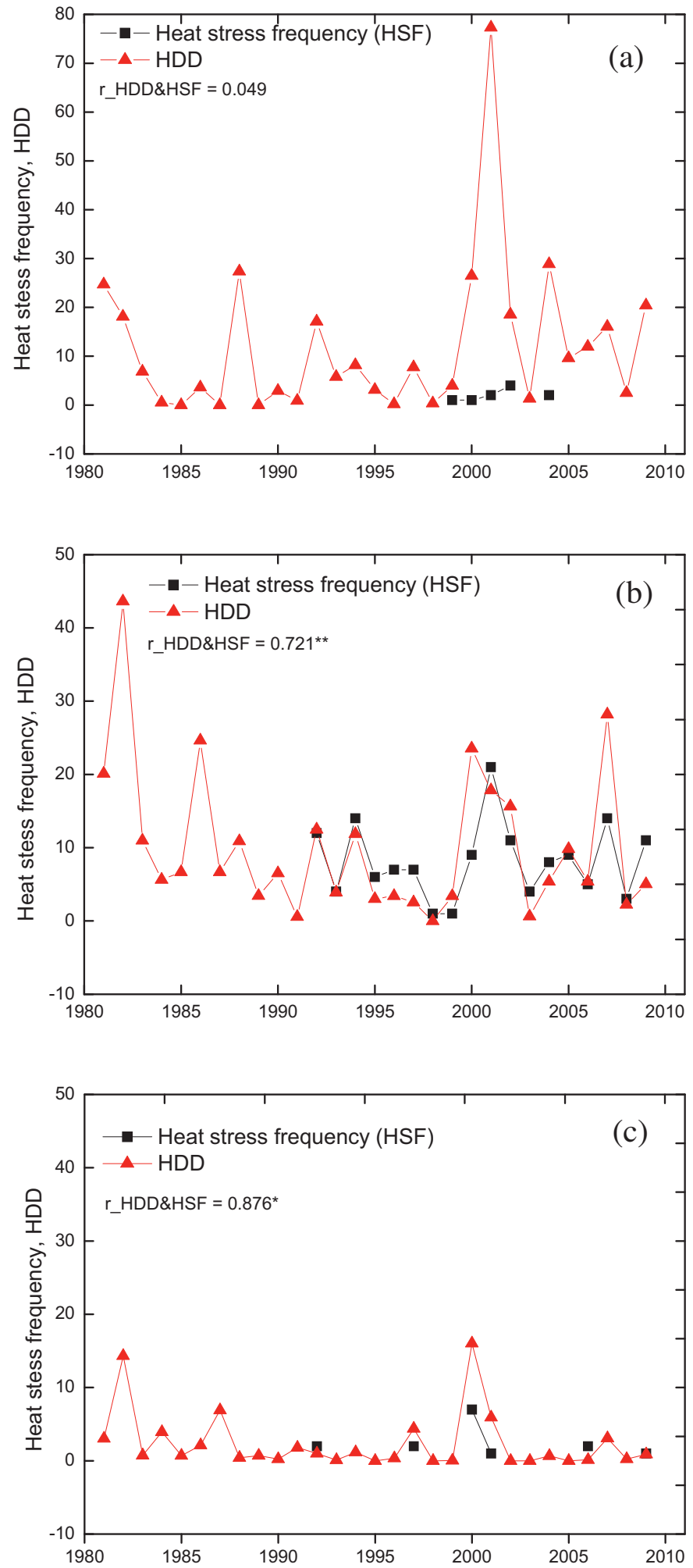

Fig. 2. Time series of heat stress occurrence frequency (HSF) and HDD in Zone I(a), Zone II (b) and Zone III (c). Correlation between HDD and HSF (r_HDD\&HSF) was also shown.

\subsection{Sensitivity of RGD and yield to GDD and HDD}

Results based on Eq. (4) showed that wheat RGD increased by $1.04,1.59$ and 2.09 days/decade in Zone I, Zone II and Zone III, respectively, during 1981-2009, due to long-term trends in climatic and non-climatic factors including cultivars changes and agro- 

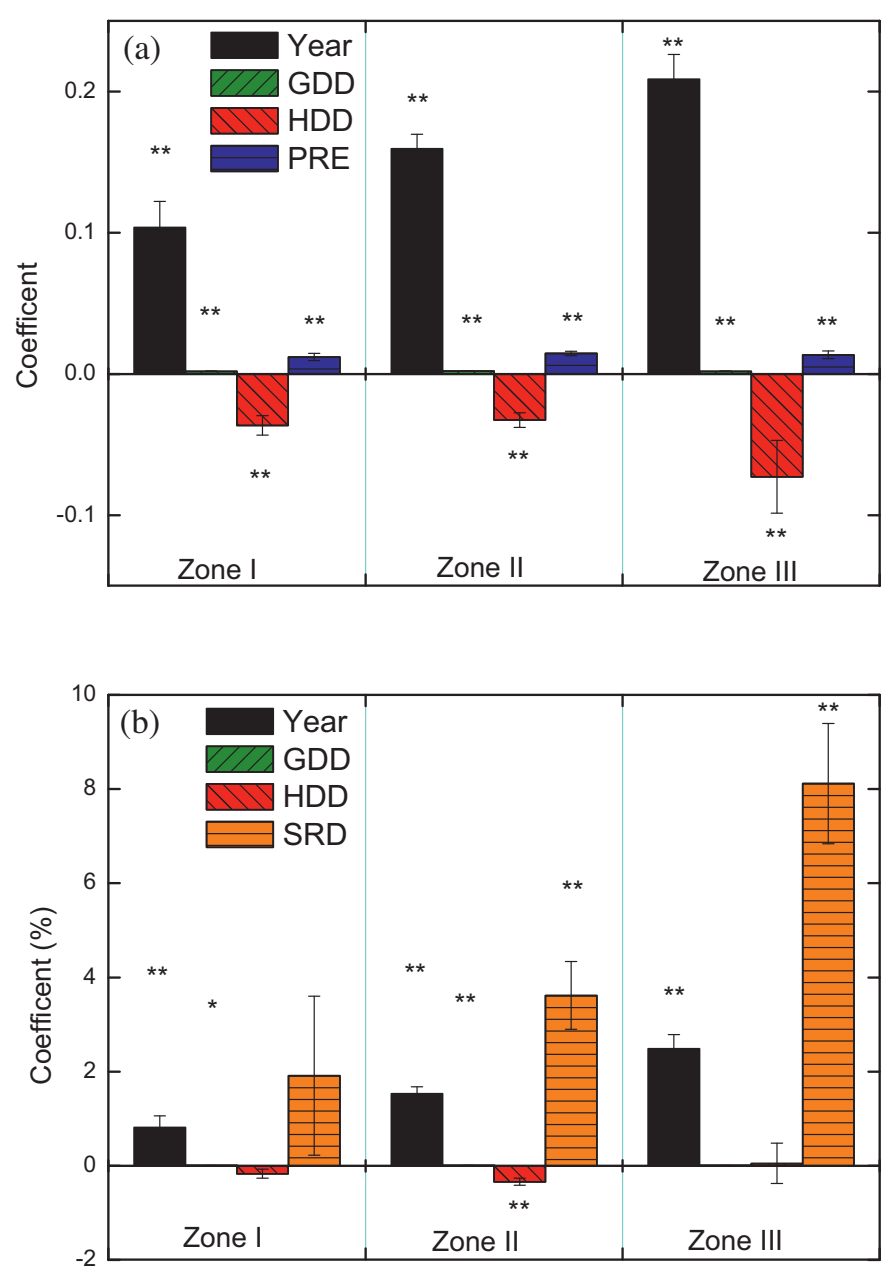

Fig. 3. Estimated coefficients for year, GDD, HDD, PRE or SRD in a regression to predict RGD (a) and a regression to predict yield (b) for wheat in Zone I, Zone II and Zone III. The coefficients with "** are significant at 0.05 level, and with "**' are significant at 0.01 level.

nomic management such as shifts of sowing dates. RGD increased significantly with increases in GDD and precipitation, however decreased significantly by $0.04,0.03$ and 0.07 days, respectively, for each one degree-hour increase in HDD from heading to maturity (Fig. 3a).

Results based on Eq. (5) showed that wheat yield increased by $0.81 \%, 1.53 \%$ and $2.49 \%$ per year in Zone I, Zone II and Zone III, respectively, due to long-term trends in climatic and non-climatic factors. It increased significantly with increase in GDD, however changed, on average, by $-0.17 \%,-0.34 \%$ and $0.051 \%$, respectively, for each one degree-hour increase in HDD from heading to maturity (Fig. 3b). It increased, on average, by $1.91 \%, 3.62 \%$ and $8.11 \%$ for each $1.0 \mathrm{MJm}^{-2}$ day $^{-1}$ increase in SRD.

\subsection{Trends in $G D D, H D D, P R E$ and $S R D$, and their effects on RGD and yield during 1981-2009}

During 1981-2009, from wheat heading to maturity, GDD increased significantly by $79.06,75.38$ and 90.90 degree-hour per year; HDD changed significantly by $0.53,-0.23$ and -0.09 degree-hour per year; precipitation decreased by $0.38,0.016$ and $0.42 \mathrm{~mm}$ per year; and SRD decreased significantly by $0.05,0.02$ and $0.03 \mathrm{MJm}^{-2} \mathrm{~d}^{-1}$ per year, in Zone I, Zone II and Zone III, respectively (Table 1 ).
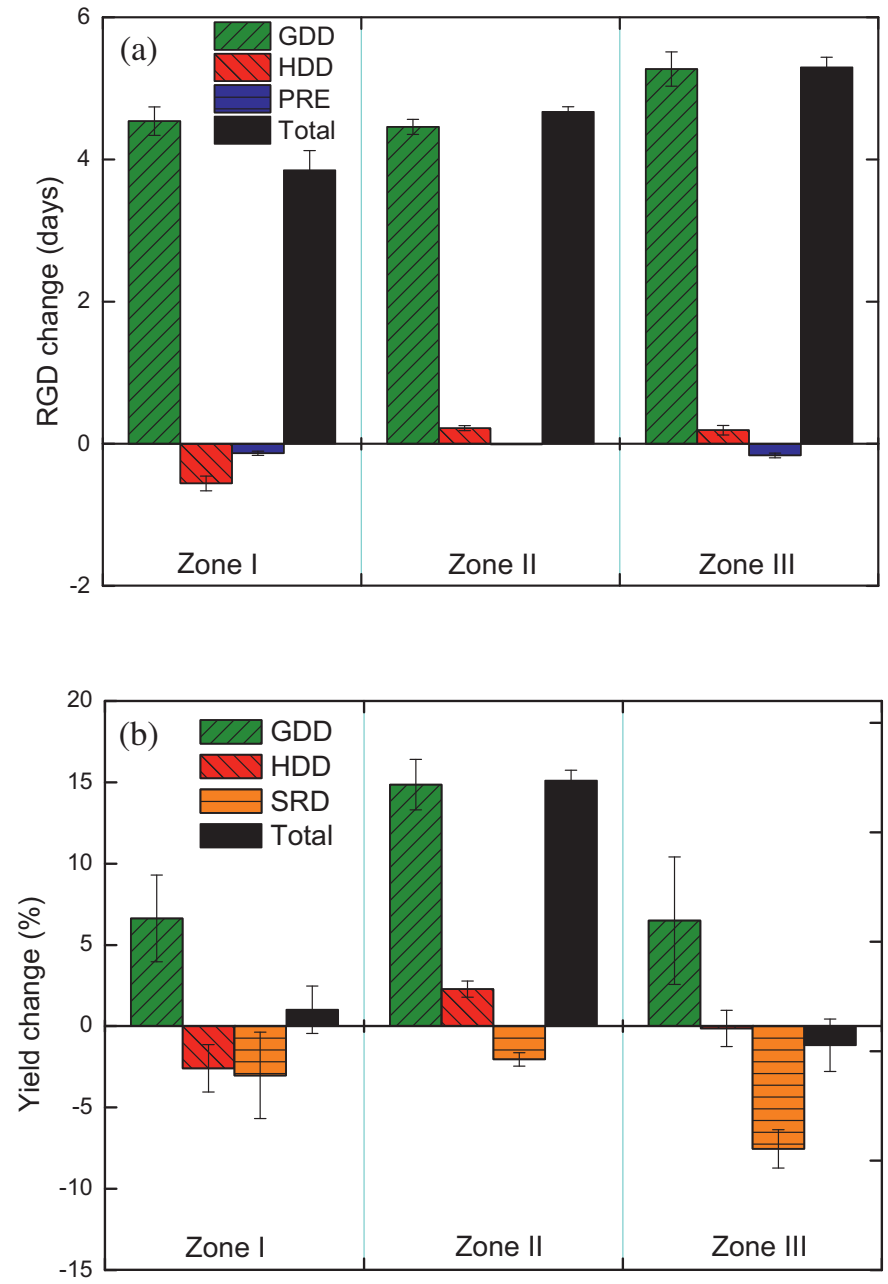

Fig. 4. Estimated changes in RGD (a) and yield (b) due to changes in GDD, HDD, PRE or SRD and their combinations during 1981-2009 for wheat in Zone I, Zone II and Zone III.

During 1981-2009, RGD increased by $4.54,4.46$ and 5.27 days in Zone I, Zone II and Zone III, respectively, simultaneously with increase in GDD. It decreased by 0.56 days for wheat in Zone I with increase in HDD, and increased by 0.22 and 0.19 days in Zone II and Zone III, respectively, with decrease in HDD. It decreased by 0.13 , 0.01 and 0.16 days in Zone I, Zone II and Zone III, respectively, due to decrease in precipitation. Finally, it increased by 3.85, 4.67 and 5.30 days in Zone I, Zone II and Zone III, respectively, with joint changes in GDD, HDD and precipitation (Fig. 4a).

During 1981-2009, wheat yield increased by $6.63 \%, 14.85 \%$ and $6.50 \%$ in Zone I, Zone II and Zone III, respectively, with increase in GDD. It declined by $2.59 \%$ in Zone I with increase in HDD, and increased by $2.30 \%$ in Zone II and declined by $0.13 \%$ in Zone III with decrease in HDD. Yield declined by 3.02\%, 2.04\% and 7.54\% in Zone I, Zone II and Zone III, respectively, due to decrease in SRD. Finally, yield increased by $1.02 \%$ and $15.09 \%$ in Zone I and Zone II respectively, however declined by $1.17 \%$ in Zone III, with joint changes in GDD, HDD and SRD (Fig. 4b).

\subsection{Effects of GDD and HDD on RGD and yield for temperature increase of $1{ }^{\circ} \mathrm{C}$ and $2{ }^{\circ} \mathrm{C}$}

For wheat in Zone I, with a temperature increase of $1^{\circ} \mathrm{C}$ and $2{ }^{\circ} \mathrm{C}$ in future, respectively, RGD may increase by 1.67 and 3.27 days with increase in GDD, however may decrease by 0.50 and 

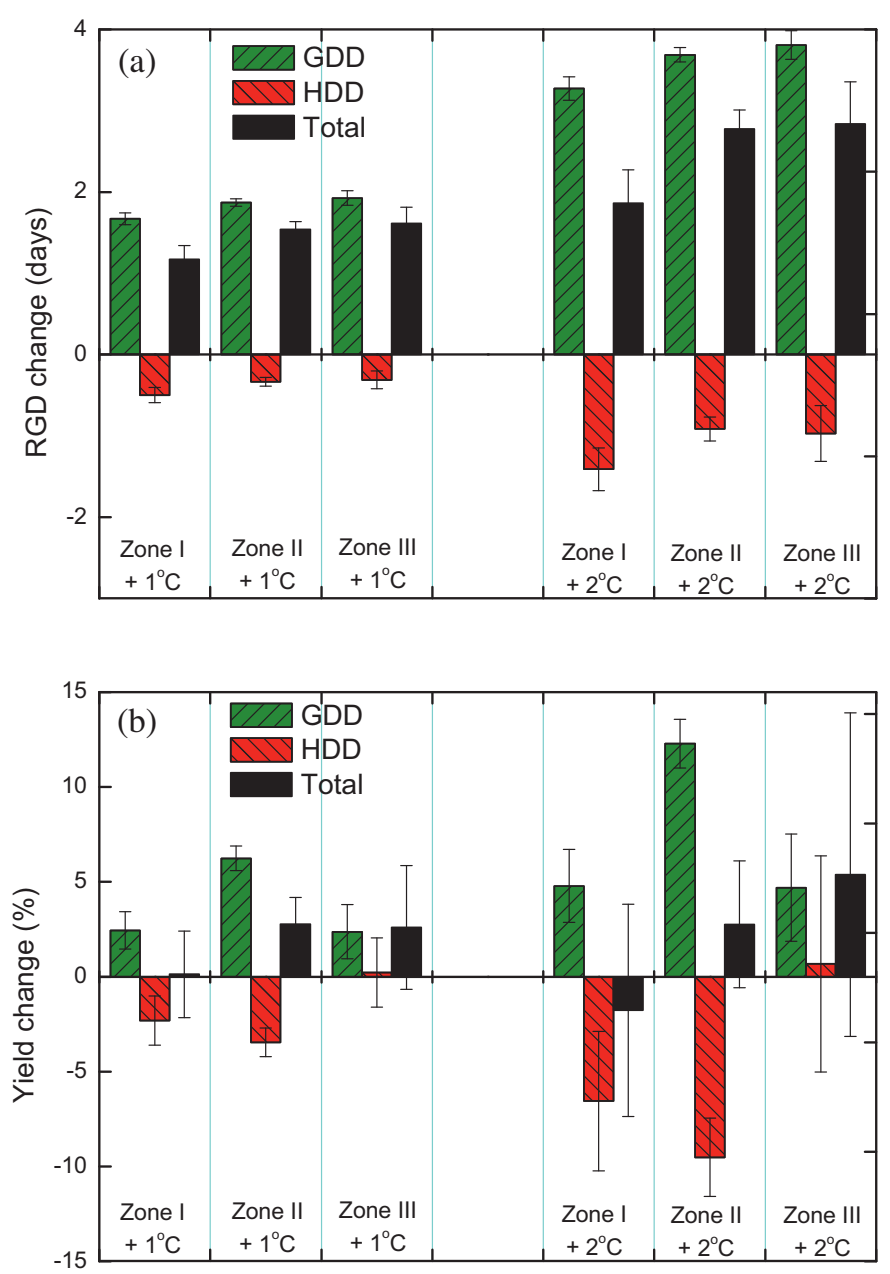

Fig. 5. Estimated changes in RGD (a) and yield (b) due to changes in GDD, HDD and their combinations for temperature increase of $1^{\circ} \mathrm{C}$ and $2^{\circ} \mathrm{C}$, respectively, for wheat in Zone I, Zone II and Zone III.

1.41 days with increase in HDD. As a result, RGD may increase by 1.17 and 1.86 days with joint increases in GDD and HDD (Fig. 5a). For wheat in Zone II, with a temperature increase of $1{ }^{\circ} \mathrm{C}$ and $2{ }^{\circ} \mathrm{C}$ in future, respectively, RGD may increase by 1.87 and 3.69 days with increase in GDD, however may decrease by 0.33 and 0.91 days with increase in HDD. As a result, RGD may increase by 1.54 and 2.77 days with joint increases in GDD and HDD, respectively (Fig. 5a). For wheat in Zone III, with temperature increase of $1^{\circ} \mathrm{C}$ and $2{ }^{\circ} \mathrm{C}$ in future, respectively, RGD may increase by 1.93 and 3.81 days with increase in GDD, however may decrease by 0.31 and 0.97 days with increase in HDD. As a result, RGD may increase by 1.61 and 2.84 days with joint increases in GDD and HDD, respectively (Fig. 5a).

For wheat in Zone I, with a temperature increase of $1{ }^{\circ} \mathrm{C}$ and $2{ }^{\circ} \mathrm{C}$ in future, respectively, yield may increase by $2.44 \%$ and $4.78 \%$ with increase in GDD, however may decrease by $2.31 \%$ and $6.55 \%$ with increase in HDD; as a result, yield may change by $0.13 \%$ and $-1.77 \%$ with joint increases in GDD and HDD, respectively (Fig. 5b). For wheat in Zone II, with a temperature increase of $1{ }^{\circ} \mathrm{C}$ and $2{ }^{\circ} \mathrm{C}$ in future, respectively, yield may increase by $6.23 \%$ and $12.28 \%$ with increase in GDD, may decrease by $3.46 \%$ and $9.52 \%$ with increase in HDD; as a result, yield may increase by $2.77 \%$ and $2.76 \%$ with joint increases in GDD and HDD, respectively (Fig. 5b). For wheat in Zone III, with a temperature increase of $1{ }^{\circ} \mathrm{C}$ and $2{ }^{\circ} \mathrm{C}$ in future, respectively, yield may increase by $2.37 \%$ and $4.69 \%$ with increase in GDD, how- ever may increase by $0.22 \%$ and $0.68 \%$ with increase in HDD; as a result, yield may increase by $2.59 \%$ and $5.37 \%$ with joint increases in GDD and HDD, respectively, however with a large variability (Fig. 5b).

\section{Discussion}

\subsection{Relative effects of GDD and HDD on RGD and yield in the HHHP}

Previous controlled-environment experiments and crop modeling studies show that crop duration shortens with increase in mean temperature if adaptation options such as changes of sowing dates and cultivars are not taken into account (Summerfield et al., 1991). A shorter crop growth duration reduces the amount of radiation that is intercepted by the leaf canopy, and hence the biomass and grain yields decline. At the sensitive growing stage, such as flowering stage, only a single day hotter than $32-35^{\circ} \mathrm{C}$, depending on how this translates into canopy temperature (Siebert and Ewert, 2014), can disrupt pollination and cause pollen sterility, reducing the number of grains that are formed, and so drastically reduce final yield (Wardlaw and Moncur, 1995; Wheeler, 2012), independent of average seasonal temperature. For instance, by controlled-environment experiments, Wardlaw and Moncur (1995) showed that high temperature resulted in a considerable drop in kernel dry weight at maturity and there was significant cultivar variation in the degree of the response, ranging from a 30 to $60 \%$ decrease in kernel dry weight at maturity for a rise in temperature from $18 / 13$ to $30 / 25^{\circ} \mathrm{C}$ (Day/night temperature). Gibson and Paulsen (1999) documented that wheat grain yield was reduced by $78 \%$, kernel number was reduced by $63 \%$, and kernel weight was reduced by $29 \%$ at $35 / 20^{\circ} \mathrm{C}$ compared with $20 / 20^{\circ} \mathrm{C}$ from 10 days after anthesis until ripeness. Tahir and Nakata (2005) showed that increase in temperature (from 30 to $38^{\circ} \mathrm{C}$ ), during reproductive phase, reduced the main stem grain weight by $20-44 \%$. Extreme high temperature does also accelerate leaf senescence; reduce crop grain-filling period and the size of grain (Harding et al., 1990; Reynolds et al., 1994; Asseng et al., 2011; Lobell et al., 2012). For instance, Yin et al. (2009) showed that $5^{\circ} \mathrm{C}$ increases in temperature above $20^{\circ} \mathrm{C}$ increased the rate of grain filling and reduced the grain filling duration by 12 days for wheat. These findings also apply for crops grown under field conditions. For example, wheat growing duration was significantly and negatively correlated with mean temperature (Tao et al., 2012b) and HDD was negatively correlated with RGD and yields in the present study.

This study however shows that it is important to consider that wheat phenological dynamics have changed in the past three decades in the HHHP. With climate warming, wheat sowing dates in the HHHP were generally delayed, heading dates were significantly advanced and maturity dates were slightly advanced under the effects of temperature, day length and cultivar changes (Fig. 6). As a result, vegetative growing duration (from sowing to heading) reduced significantly, and RGD increased significantly, which, together with increase in temperature, cause GDD during RGP to increase significantly. Then yields increased accordingly. In the meantime, heat stress reduced RGD in all the three zones, and had damage on wheat yield in Zone I and Zone II. In Zone III, the limiting factors for wheat production were continuous precipitation and low SRD (Tao et al., 2012b); there was a positive correlation between yield and HDD because HDD was positively correlated with SRD. During 1981-2009, heat stress and HDD during RGP increased in Zone I, however decreased in Zone II and Zone III due to advances in heading dates and maturity dates. In addition, intensive irrigation in the region also had a significant cooling effect of $0.17-0.20^{\circ} \mathrm{C} \mathrm{decade}^{-1}$ on average daily maximum 

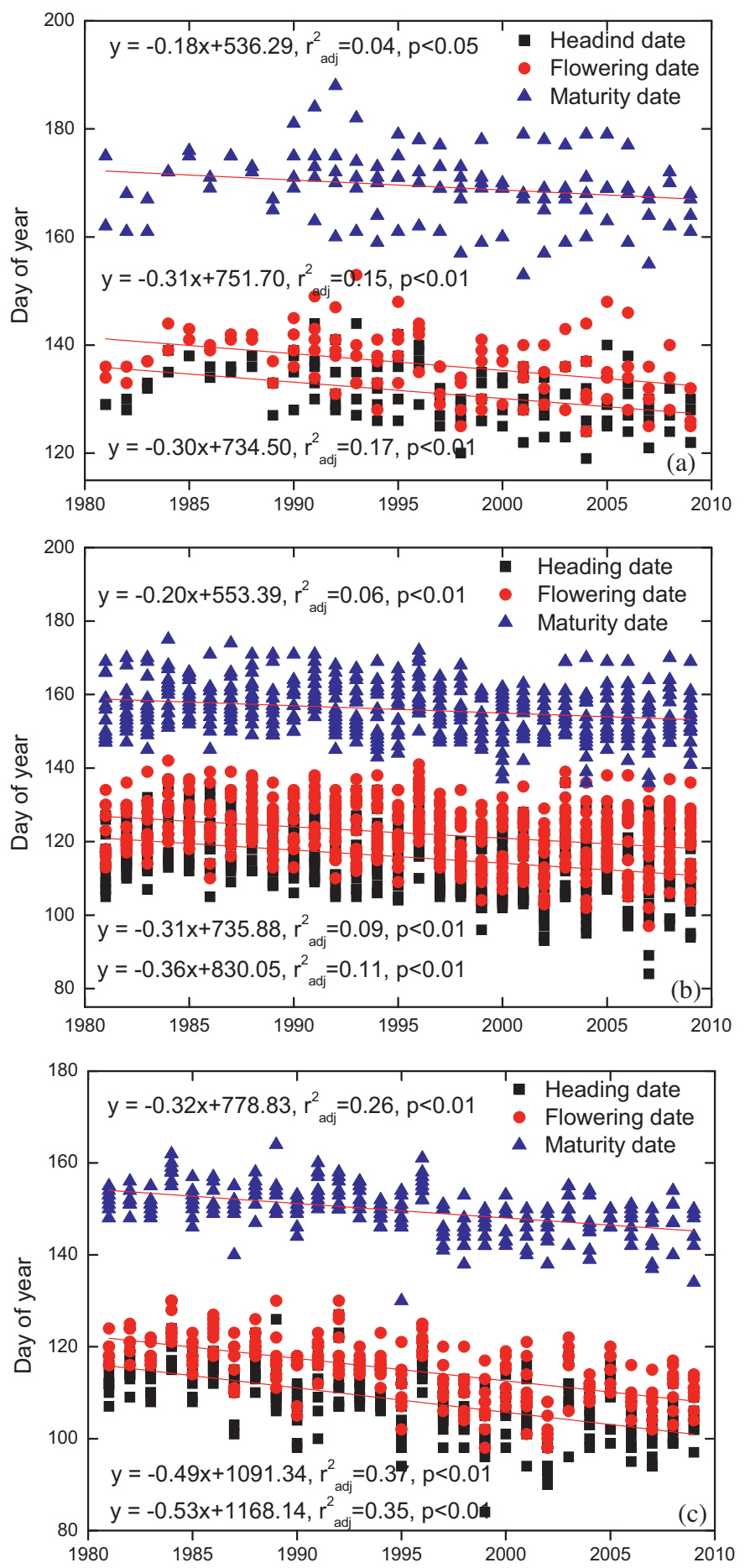

Fig. 6. Time series of heading date, flowering date and maturity date from 1981 to 2009 for the stations in Zone I (a), Zone II (b) and Zone III (c).

temperature (Shi et al., 2014). Increase in HDD had damage on wheat yield in Zone I and yield was benefited from decrease in HDD in Zone II. In general, increases in GDD contributed most and decreases in SRD contributed secondarily to yield change during the study period in the HHHP, suggesting that interactions between cultivars changes and climate warming contribute most to yield increase by increasing GDD and reducing HDD. This finding is supported by a field experiment with supplemental infrared heating in the region, which documented that artificial warming by $2.5^{\circ} \mathrm{C}$ in field conditions in Zone 1 increased winter wheat growth and yield significantly (Fang et al., 2015). Nevertheless, we did find
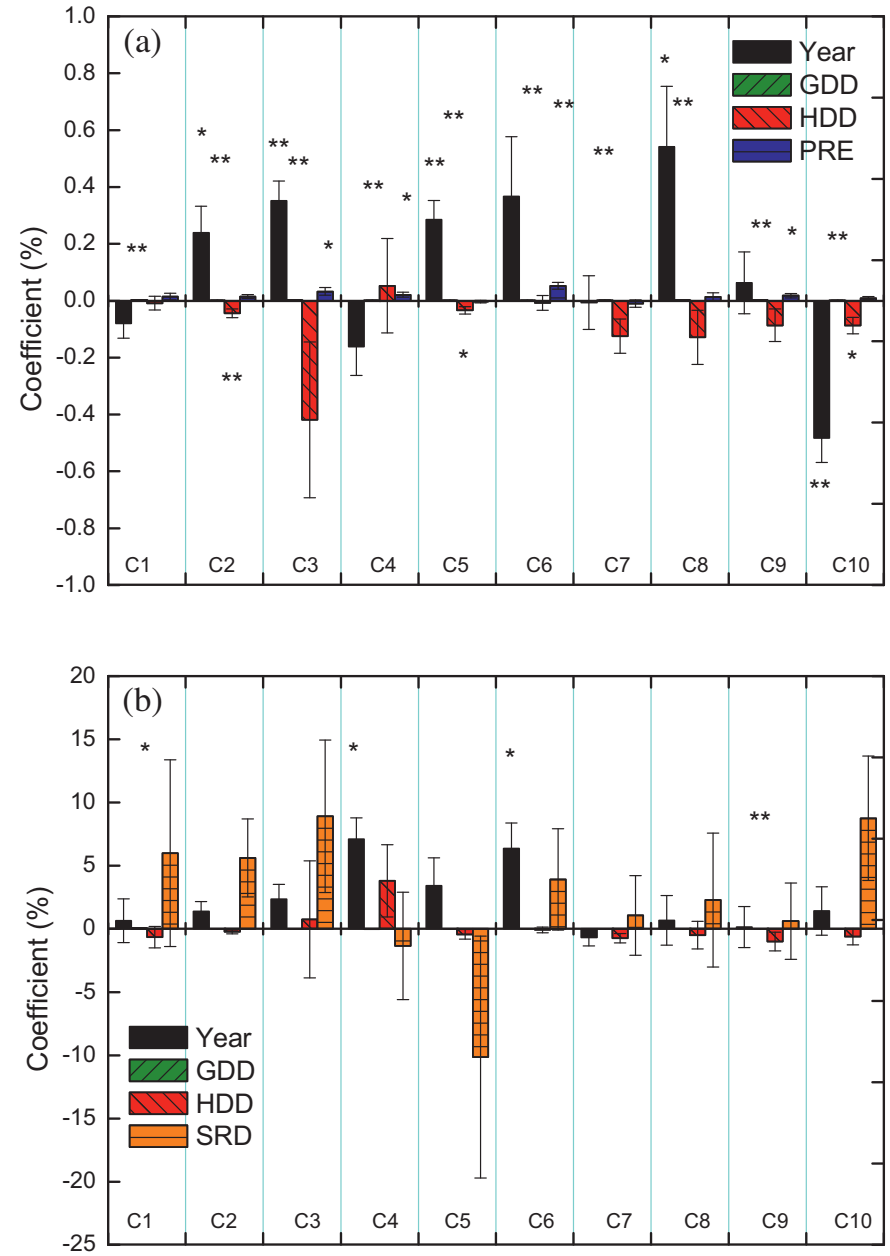

Fig. 7. Estimated coefficients for year, GDD, HDD, PRE or SRD in a regression to predict RGD (a) and a regression to predict yield (b) for ten wheat cultivars, i.e. C1, $\mathrm{C} 2, \mathrm{C} 3, \mathrm{C} 4, \mathrm{C} 5, \mathrm{C}, \mathrm{C} 7, \mathrm{C} 8, \mathrm{C} 9$ and $\mathrm{C} 10$. The information on the ten wheat cultivars was presented in the supplementary material. The coefficients with '*' are significant at 0.05 level, and with '**', are significant at 0.01 level.

heat stress had negative impacts on RGD and yield even in a setting with farmers' autonomous adaptations. Heat stress may reduce yield substantially in a hot year resulting in large inter-annual yield variability. Furthermore, heat stress may increase with climate warming and offset the positive impacts from GDD increase, eventually resulting in a net yield loss in northern part of the HHHP. Crop physiologists and plant-breeders should look for improved heat tolerance in wheat cultivars (Craufurd et al., 2011; Semenov et al., 2014). The adaptation of crops to hot day temperatures should be a top priority for research that is needed to maintain crop productivity under climate change (Siebert and Ewert, 2014).

\subsection{Variations in sensitivity of different cultivars, shifts of phenological dates and the implication for adaptations}

The above estimations were based on long-term experimental data across different cultivars. Different cultivars can have different sensitivity to heat stress and drought stress (Amani et al., 1996; Jagadish et al., 2010). Further analyses showed that the RGD and yield of the popularly used cultivars had quite large variations in response to GDD and HDD, as well as in long-term trends due to climatic and non-climatic factors (Fig. 7a). For example, from the popularly used ten wheat cultivars in the HHHP, in terms of RGD, C2, C5 and C10 were the most sensitive cultivars to HDD, and C1, C4 and C6 were the most tolerant cultivars to HDD (Fig. 7a). RGD of 
C10 decreased most due to long-term trends in climatic and nonclimatic factors. In terms of yield, C7 and C9 were the most sensitive cultivars to HDD, and C2, C4 and C6 were the most tolerant cultivars to HDD (Fig. 7b). Yield of C4 and C6 increased most, and yield of C7 decreased most, due to long-term trends in climatic and nonclimatic factors. The ecological, biological and physiological traits of these cultivars should be further investigated to provide information for agronomists to design adaptation strategies, and for crop breeding scientists to breed more tolerant cultivars to coping with climate change and heat stress.

In the HHHP, wheat cultivars have been frequently renewed for every 3-5 years and wheat phenology has changed notably under the combined effects of climate change, day length and agronomic management practices (Tao et al., 2012b). Such changes increased significantly the GDD during reproductive growing period and reduced HDD in the middle and southern parts of HHHP under ongoing climate change, suggesting that the shifts in crop cultivars and phenological dynamics increase wheat production and reduce heat stress impacts. Our findings that increase of HDD in Zone I and decrease of HDD in Zone II and Zone III are consistent with the observed records of heat stress occurrence frequency at the agricultural meteorological stations documented by Zhang et al. (2014). If the yearly wheat phenological dynamics were not taken into account, the results could be quite different. For example, Liu et al. (2014) found heat stress between heading and maturity had increased in the last decades in most of the main winter wheat production areas of China based on indices calculated within a fixed time period throughout the last decades. Therefore, climate change impact study should be elaborated to take into account the farmlevel adaptations such as shifts crop cultivars and cropping system dynamics. The insights into crop response and adaptation to climate change and climate extremes in the past three decades have important implications for improving climate impact study and designing adaptation for the future.

\section{Conclusions}

The datasets used in the study cover a larger number of experiment stations and a longer time period. The greater scope of our dataset in both spatial and temporal dimensions positions us to gain insights into crop response and adaptation to climate change in the past three decades, and estimate the effects of heat stress on wheat yields more precisely and with less bias. Different from most previous studies, here, we took into account the shifts of crop cultivars and cropping system dynamics while quantifying the impacts of climate change and heat stress on crop growth and yield. Our findings suggest that wheat production was generally benefited from climate change and heat stress was reduced by using new better suited cultivars and adjusted agronomic management practices, in the past three decades in the HHHP. Increases in GDD contributed most and decreases in SRD contributed secondarily to yield change. Nevertheless, heat stress may increase with climate warming, offset a large portion of the benefits from increases in mean temperature, and eventually lead to yield reduction in some regions. Our findings highlight that the farm-level adaptations such as shifts of crop cultivars and cropping system dynamics should be taken into account to improve climate change impact study. The insights into crop response and adaptation to climate change and climate extremes in the past three decades provide excellent evidences and basis for improving climate change impact study and designing adaptation measures for the future.

\section{Acknowledgements}

This study is supported by the National Science Foundation of China (Project No. 41571088 and No. 41571493). Funding support by FACCE MACSUR project through the Finnish Ministry of Agriculture and Forestry is also gratefully acknowledged. We thank greatly Pytrik Reidsma (Wageningen University) for insightful comments and discussions. We are grateful to the two anonymous reviewers and editor for their insightful comments on an earlier version of this manuscript.

\section{Appendix A. Supplementary data}

Supplementary data associated with this article can be found, in the online version, at http://dx.doi.org/10.1016/j.eja.2015.08.003.

\section{References}

Amani, J., Fischer, R.A., Reynolds, M.P., 1996. Canopy temperature depression association with yield of irrigated spring wheat cultivars in a hot climate. J. Agron. Crop Sci. 176, 119-129.

Asseng, S., Foster, I., Turner, N.C., 2011. The impact of temperature variability on wheat yields. Global Change Biol. 17, 997-1012.

Asseng, S., Ewert, F., Martre, P., Rotter, R.P., et al., 2015. Rising temperatures reduce global wheat production. Nat. Clim. C 5, 143-147.

Challinor, A.J., Wheeler, T.R., Craufurd, P.Q., Slingo, J.M., 2005. Simulation of the impact of high temperature stress on annual crop yields. Agric. For. Meteorol. $135,180-189$

China Meteorological Administration, 1993. Agro-meteorological Observation Standard. China meteorological press, Beijing, pp. 44-50.

Craufurd, P.Q., Vadez, V., Krishna Jagadish, S.V., Vara Prasad, P.V., Zaman-Allah, M., 2011. Crop science experiments designed to inform crop modeling. Agric. For. Meteorol. 170, 8-18.

Fang, S., Cammarano, D., Zhou, G., Tan, K., Ren, S., 2015. Effects of increased day and night temperature with supplemental infrared heating on winter wheat growth in North China. Eur. J. Agron. 64, 67-77.

Gibson, L.R., Paulsen, G.M., 1999. Yield components of wheat grown under high temperature stress during reproductive growth. Crop Sci. 39, 1841-1846.

Gourdji, S.M., Sibley, A.M., Lobell, D.B., 2013. Global crop exposure to critical high temperatures in the reproductive period: historical trends and future projections. Environ. Res. Lett. 8, 024041.

Harding, S.A., Guikema, J.A., Paulsen, G.M., 1990. Photosynthetic decline from high temperature stress during maturation of wheat: I. Interaction with senescence processes. Plant Physiol. 92, 648-653.

Jagadish, S.V., Muthurajan, R., Oane, R., Wheeler, T.R., Heuer, S., Bennett, J., Craufurd, P.Q., 2010. Physiological and proteomic approaches to address heat tolerance during anthesis in rice (Oryza sativa L.). J. Exp. Bot. 61, 143-156.

Liu, B., Liu, L., Tian, L., Cao, W., Zhu, Y., Asseng, S., 2014. Post-heading heat stress and yield impact in winter wheat of China. Global Change Biol. 20, 372-381.

Lobell, D.B., Schlenker, W., Costa-Roberts, J., 2011. Climate trends and global crop production since 1980. Science 333, 616-620.

Lobell, D.B., Sibley, A., Ortiz-Monasterio, J.I., 2012. Extreme heat effects on wheat senescence in India. Nat. Clim. Change 2, 186-189.

Olesen, J., Trnka, M., Kersebaum, K., Skjelvag, A., Seguin, B., Peltonen-Sainio, P., Rossi, F., Kozyra, J., Micale, F., 2011. Impacts and adaptation of European crop production systems to climate change. Eur. J. Agron. 34, 96-112.

Ortiz, R., Sayre, K.D., Govaerts, B., Gupta, R., Subbarao, G.V., Ban, T., Hodson, D., Dixon, J.M., Ortiz, M.J.I., Reynolds, M., 2008. Climate change: can wheat beat the heat? Agric. Ecosys. Environ. 126, 46-58.

Porter, J.R., Gawith, M., 1999. Temperatures and the growth and development of wheat: a review. Eur. J. Agron. 10, 23-36.

Prescott, J.A., 1940. Evaporation from a water surface in relation to solar radiation. Trans. R. Soc. Sci Australia 64, 114-125.

Reidsma, P., Ewert, F., Lansink, A.O., Leemans, R., 2010. Adaptation to climate change and climate variability in European agriculture: the importance of farm level responses. Eur. J. Agron. 32, 91-102.

Reynolds, M.P., Balota, M., Delgado, M.I.B., Amani, I., Fischer, R.A., 1994. Physiological and morphological traits associated with spring wheat yield under hot, irrigated conditions. Aust. J. Plant Physiol. 21, 717-730.

Rötter, R.P., Carter, T.R., Olesen, J.E., Porter, J.R., 2011. Crop-climate models need an overhaul. Nat. Clim. Change 1, 175-177.

Semenov, M.A., Stratonovitch, P., Alghabari, F., Gooding, M.J., 2014. Adapting wheat in Europe for climate change. J. Cereal Sci. 59, 245-256.

Shi, W., Tao, F., Liu, J., 2014. Regional temperature change over the Huang-Huai-Hai Plain of China: the roles of irrigation versus urbanization. Int. J. Clim. 34, 1181-1195.

Siebert, S., Ewert, F., 2012. Spatiotemporal patterns of phenological development in Germany in relation to temperature and day length. Agric. For. Meteorol. 152, 44-57. 
Siebert, S., Ewert, F., 2014. Future crop production threatened by extreme heat. Environ. Res. Lett. 9, 041001.

Summerfield, R.J., Roberts, E.H., Ellis, R.H., Lawn, R.J., 1991. Towards the reliable prediction of time to flowering in six annual crops. I. The development of simple models for fluctuating field environments. Exp. Agr. 27, 11-31.

Tahir, I.S.A., Nakata, N., 2005. Remobilization of nitrogen and carbohydrate from stems of bread wheat in response to heat stress during grain filling. J. Agron. Crop Sci. 191, 106-115.

Tao, F., Yokozawa, M., Xu, Y., Hayashi, Y., Zhang, Z., 2006. Climate changes and trends in phenology and yields of field crops in China 1981-2000. Agric. For. Meteorol. 138, 82-92.

Tao, F., Yokozawa, M., Zhang, Z., 2009. Modelling the impacts of weather and climate variability on crop productivity over a large area: a new process-based model development, optimization, and uncertainties analysis. Agric. For. Meteorol. 149, 831-850.

Tao, F., Zhang, Z., Zhang, S., Zhu, Z., Shi, W., 2012a. Response of crop yields to climate trends since 1980 in China. Clim. Res. 54, 233-247.

Tao, F., Zhang, S., Zhang, Z., 2012b. Spatiotemporal changes of wheat phenology in China under the effects of temperature, day length and cultivar thermal characteristics. Eur. J. Agron. 43, 201-212.

Tao, F., Zhang, Z., 2013. Climate change, wheat productivity and water use in the North China Plain: a new superensemble-based probabilistic projection. Agric. For. Meteorol. 170, 146-165.

Tong, P.Y., 1992. Wheat Cultivation Zones of China. China Agricultural Science and Technology Press, Beijing, pp. 295

Trnka, M., Rotter, R.P., Ruiz-Ramos, M., Kersebaum, K.C., Olesen, J.E., Zalud, Z., Semenov, M.A., 2014. Adverse weather conditions for European wheat production will become more frequent with climate change. Nature Clim. Change 4, 637-643.

Wall, G.W., Kimball, B.A., White, J.W., Ottman, M.J., 2011. Gas exchange and water relations of spring wheat under full-season infrared warming. Global Change Biol. 17, 2113-2133.

Wardlaw, I., Moncur, L., 1995. The response of wheat to high temperature following anthesis. I. The rate and duration of kernel filling. Funct. Plant Biol. 22, 391-397.

Wheeler, T., 2012. Wheat crops feel the heat. Nat. Clim. C 2, 152-153.

Yin, X., Guo, W., Spiertz, J.H., 2009. Aquantitative approach to characterize sink-source relationships during grain filling in contrasting wheat genotypes. Field Crops Res. 114, 119-126.

Zhang, Z., Wang, P., Chen, Y., Zhang, S., Tao, F., Liu, X., 2014. Spatial pattern and decadal change of agro-meterological disasters in the main wheat production area of China during 1991-2009. J. Geog. Sci. 24, 387-396. 